\title{
BIM OBJECTS LIBRARY FOR INFORMATION EXCHANGE IN PUBLIC WORKS: THE USE OF PROPRIETARY AND OPEN FORMATS
}

\author{
AMBRA BARBINI ${ }^{1,2}$, GIADA MALACARNE ${ }^{1}$, GIOVANNA MASSARI $^{2}$, \\ GABRIELE PASETTI MONIZZA ${ }^{1}$ \& DOMINIK T. MATT ${ }^{1,3}$ \\ ${ }^{1}$ Fraunhofer Italia Research, Italy \\ ${ }^{2}$ University of Trento, Italy \\ ${ }^{3}$ Free University of Bolzano, Italy
}

\begin{abstract}
The Italian code of public procurement states that interoperability via open formats is essential for the exchange of information between public organizations and their project partners. However, the understanding of what interoperability means and the use of open formats in the current practice is still limited. Moreover, one of the approaches that a public organization can adopt to share its information requirements among project partners is via parametric objects, such as BIM families. This approach is not commonly adopted, it is very time consuming, but it allows the integration of the client's requirements directly into the project. This paper aims at investigating whether a BIM objects library can be the solution to facilitate the interoperability in information exchange between public organizations and their project partners. The paper shows a parallelism between the use of the proprietary and the open format when using BIM objects in a project environment comparing the open and the proprietary format of a BIM object library in terms of interoperability. This research refers to a case study consisting of the development of a BIM objects library for a public organization in Italy. The results shows that both proprietary and open formats are an efficient solution when developing a BIM library for a public organization. However, their usefulness depends on the way the public organization choose to organize its own BIM adoption.
\end{abstract}

Keywords: BIM objects, BIM Library, public works, interoperability, open format.

\section{INTRODUCTION}

The public sector is considered as a key player in leading the industry towards BIM adoption [1]. In fact, BIM implementation increases intensively as more and more public organizations around the world require the use of BIM in their projects and develop BIM standards [2].

In Italy, in 2016, the national code of public procurement (D.lgs 50/2016) has introduced, for the first time, the use of specific electronic modelling methods and tools in public works 0 . This documents state that, when procuring public works, an organization must declare its information requirements in a way which assure the interoperability of the process using open, non-proprietary formats.

On the one hand, interoperability via open formats is essential for the exchange of information between public organizations and their project partners in order to facilitate competition between technology providers and the involvement of technical professionals 0 . However, despite of the special attention paid by the norm on this matter, the understanding and its use in the current practice is still limited. A previous investigation, aimed at understanding the level of knowledge and adoption of BIM in a specific region of Italy, shows that the $44 \%$ of the respondents are already working with BIM software but only the $10 \%$ use open formats. This situation unveils a gap in BIM adoption within the region - only $16 \%$ of the respondents declares to use BIM - highlighting that there is the need to facilitate the understanding on interoperability and the use of open formats for a full adoption of BIM [1]. 
On the other hand, existing BIM implementation actions taken by the public sector shows that there are three approaches that a client can adopt to share its information requirements among project partners: (1) via pdf documents, such as the BIM Execution Plan (BEP) document [2], [4]; (2) via excel sheets, where information requirements are listed in a tabular way, such as COBie spreadsheets [2], [4]; (3) via parametric objects, such as BIM families [4]. The first two approaches are analogue and often not exhaustive [4]. The third approach implies that the client shares with its project partners a BIM objects library containing all its requirements as geometrical and alphanumerical data. This approach is not commonly adopted, it is very time consuming, but it allows to integrate the client's requirements directly into the project [4].

We would like to investigate whether BIM objects libraries can be the solution to facilitate the interoperability in information exchange between public organizations and their project partners. Therefore, this research aims at developing a BIM objects library, for the information exchange between a public organization and its project partners, assuring the interoperability of the process.

\section{STATE OF THE ART}

The Italian standard UNI 11337-1 defines BIM objects library as a digital environment for gathering and sharing graphic and alphanumeric model objects. BIM objects are virtualizations of geometric and non-geometric attributes, related to physical or spatial entities, associated to a set of works, and to their processes [6]. Scientific literature defines library in several ways: Afsari describes the BIM libraries as "source for building product model organized synthetically and systematically" [7], while Shin defines the BIM library as "an organized group of BIM objects where the building information is stored" [8]. Afsari and Shin highlight that information and especially exchange of information is a key aspect of BIM library. BIM objects can be the container for exchanging information, and open format files can guarantee technical interoperability and software independency, as Hjelseth has suggested [9]. However, in current practice, information flow is neither automated nor seamless, as the theory illustrates [10] and it has been estimated that, in 2002, inadequate interoperability caused an annual cost of $\$ 15.8$ billion in the U.S. capital facilities industry [11].

However, after the introduction of Revit ${ }^{\circledR}$ Families as primary elements, several BIM objects catalogues have been developed [12], turning the design process from drawing into an assembling elements process [13]. Each element represents a building component and includes not only a 3D model, but also several information [9]. According to UNI EN ISO 11337-4, BIM objects can be generic or specific. Generic BIM objects are entities displayed as generic geometric systems or through their overall dimensions, with approximate quantitative and qualitative features. Specific BIM objects are entities graphically virtualized as specific geometric systems, in which the quantitative and qualitative features are linked to a defined product [14]. An example of an open BIM library of specific objects is BIMobject ${ }^{\circledR}$. BIMobjects ${ }^{\circledR}$ provides BIM objects as virtual prototypes of real building components developed in several file formats both proprietary and open. This should improve the efficiency of the construction project integrating building components in the early design stage of the project. Moreover, private and public client organizations are developing their own BIM library. Deutsche Bahn developed a BIM objects library to support the design of small and medium train stations in Germany. Deutsche Bahn has collected generic objects of the BIM library in a Revit ${ }^{\circledR}$ master project, adopting the IFC file format for open information exchange [1]. In the United Kingdom, the government has promoted the development of the NBS BIM National Library as a BIM objects platform to support the BIM 
adoption in the AEC sector. The NBS National BIM Library is a catalogue of generic and specific BIM objects [1]. The NBS National Library promotes the complementary use of generic and specific BIM objects in order to facilitate the integration of the whole construction supply chain - from planners to specific products providers - starting from the early design phase of a project. It can be stated that, in public works, using generic BIM objects can help from the design phase to the construction site [17], while the use of specific objects can be significant for the facility management along the life cycle of the built objects [18]. Therefore, since in Italy BIM is progressively becoming mandatory for public works, public organizations could also be interested in developing their own BIM objects libraries.

Evidences from the experiences in developing BIM objects catalogues and the findings from academic research shows two approaches that can be adopted to manage the interoperability issue:

- developing the library in several proprietary format;

- developing a reliable open format version of the library.

\section{RESEARCH METHOD}

In order to compare the effectiveness of the proprietary and the open file formats in exchanging information between a public organization and its project partners, the research has performed a parallelism between the use of the proprietary and the open format when using BIM objects in a project environment.

After the selection of specific components in the project environment (see Section 3.1) to be converted into BIM objects, the research activities consisted in three main steps:

- The first step consisted in selecting the tasks to be performed in the project environment, in identifying all the information required to perform the selected tasks and in associating this information to the selected components (see Section 3.2).

- During the second step, each selected component has been modelled into a BIM object, integrating the information identified in step 1 and generating the BIM library, both in proprietary and in open format (see Section 3.3).

- The third step consisted in simulating project partner's interaction with the library, when performing the selected tasks in the project environment, and in performing a parallelism between the formats of the library (see Section 3.4).

\subsection{Selection of specific components in the project environment}

The context of the research project was the development of an urban mobility project located in a South Tirolean municipality, in the North of Italy. The public organization, responsible for the project development, expressed their willingness to adopt BIM, as a methodology to optimize the information workflow during the project development and to facilitate the generation of documents and information for the facility management department after the project close-out. Within this context, one of the BIM activities focused on the development of a BIM objects library.

One of the requirements of the project was the mandatory use of the public organization' Corporate Design components. The Corporate Design of the public organization consists in 30 standardized components of urban furniture: benches, info points, bus shelter, bike parking boxes, clocks and signs. Figure 1: provides an overview on a part of the components of the Corporate Design. Since these components are characterized by a high level of standardization and will increase in number of presences around the region in the next years, the research team decided to use these components for the scope of the research. 


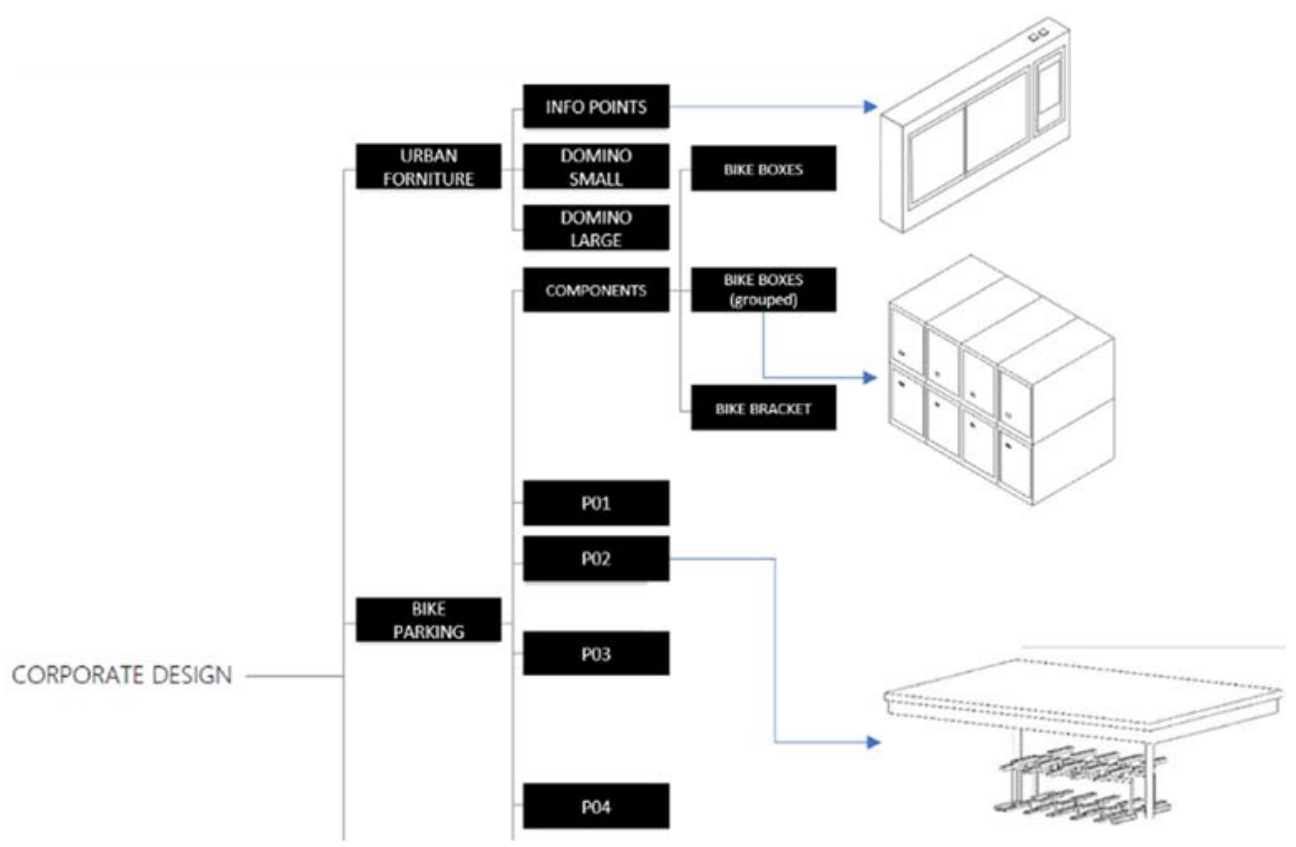

Figure 1: Components of the corporate design.

3.2 Step 1: Tasks to be performed in the project environment, list of information required and association to the selected components

Once selected the components to convert into BIM objects, the study focused on: selecting the project tasks to perform using these BIM objects; identifying the information required to perform the tasks selected and associating this information to the components.

The public organization selected the tasks to be performed according to their needs along a project lifecycle. Generally, the BIM objects will play a role during the design phase, the tendering for construction and the facility management phase. In this paper, the authors present the results from the analysis of the design phase. Referring to the design phase, the research team identified three tasks:

- Positioning the objects in the project environment.

- Calculating quantities.

- Calculating costs.

Each of the information required by the public organization has been classified primary per type (geometric, alphanumeric, document related) and per decision phase (fixed - information always valid/no decision required - design, tender, facility management). This resulted in several excel spreadsheets (one per component) where all the information required are collected. An example of the spreadsheets obtained is illustrated in Figure 2: . 


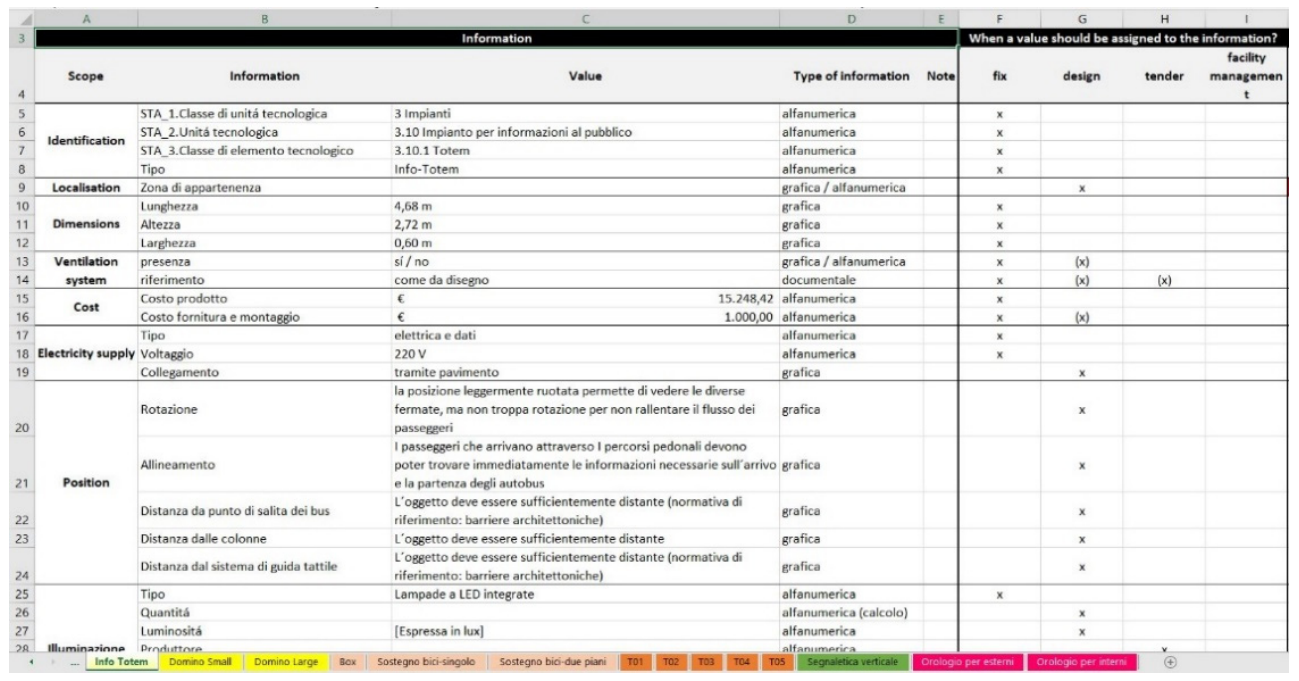

Figure 2: Example of an excel spreadsheet with the list of information required by the public organization.

\subsection{Step 2: The generation of the BIM library}

To develop the library in proprietary format we used the release 2018 of the software Autodesk Revit ${ }^{\mathbb{R}}$. The adopted process is illustrated in Figure 3: and can be described as follows: we modelled each component of the Corporate Design within the category "Generic Model" as single Revit ${ }^{\circledR}$ Family. Then we nested the components in a main Revit Family, wherein all the information associated to each component have been modelled.

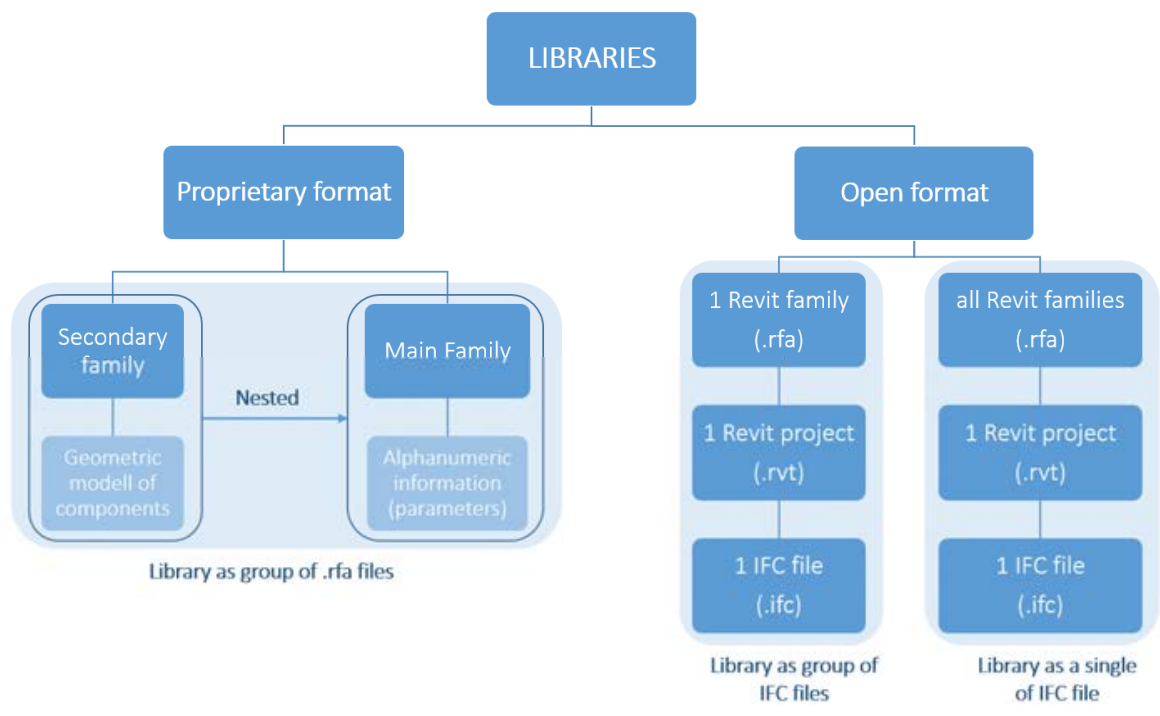

Figure 3: Research method, step two: the creation of the libraries. 
We created the open format of the library, exporting IFC files of the library, after loading the objects in a Revit ${ }^{\circledR}$ Project file. As illustrated in Figure 4: we generated the open format library following two different approaches, in order to have a wider view on IFC limits and potentials. With the first approach, the library consists in a group of files, where each file contains a single BIM object - each Revit Family has been loaded in a different Revit ${ }^{\circledR}$ Project file. With the second approach, the library consists of a single project file gathering all the BIM objects - all the Revit ${ }^{\mathbb{B}}$ Families have been loaded in a single Revit ${ }^{\circledR}$ Project file. In both cases, during the export of the Revit ${ }^{\mathbb{B}}$ Project file, the IFC version "IFC $2 \times 3$ Coordination View 2.0" has been duplicated, switching the Property Sets from "Export IFC common property sets" to "Export Revit ${ }^{\circledR}$ property sets".

Through the IFC viewer BIMvision, each IFC file has been checked in order to test missing geometries and/or information. Moreover, the IFC files have also been opened in the three BIM software Revit ${ }^{\mathbb{R}}$, Allplan ${ }^{\circledR}$ and Archicad $^{\circledR}$ to evaluate the effective possibility to exchange information between different BIM software using IFC format.

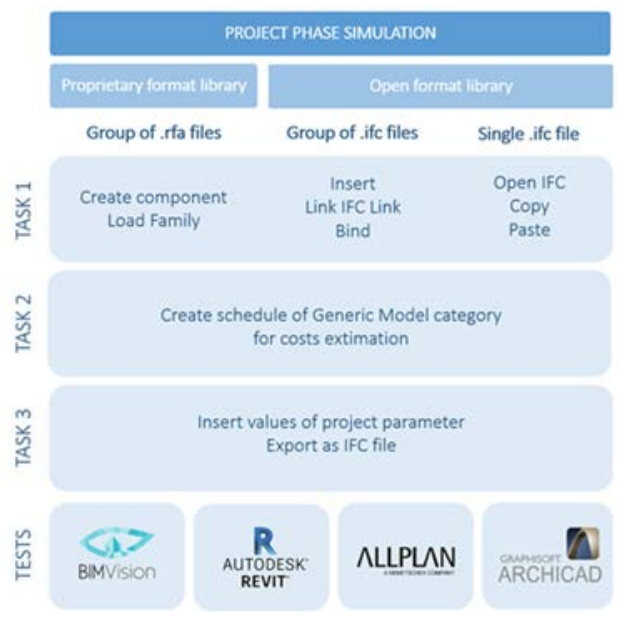

Figure 4: Research method, step 3: diagram of the workflow.

\subsection{Step 3: Parallelism between the formats of the library}

In the future, the public organization will share the BIM library with its project partners. The partners will complete the information required directly into the BIM objects and will share the updated BIM library with the public organization. This kind of workflow will require several exchanges of information and a public organization must guarantee an efficient exchange of information. Therefore, the third step of the research consisted in performing a simulation of the tasks selected in step 1 using the three libraries developed in step 2 (the group of files in proprietary format, the group of files in open format, the single file in open format) and in comparing the results obtained. The tasks, selected in step 1, have been simulated comparing the use of proprietary and the open format in a BIM project environment (Revit $^{\circledR}$ 2018), as described in the following steps:

1. Positioning the objects in the project environment.

2. Creating a quantity schedule and a cost schedule.

3. Exporting an IFC file after completing project information. 
In the first step, the workflow differs depending on the type of library used:

- The BIM objects in proprietary format have been loaded as Revit ${ }^{\circledR}$ Family in the project environment.

- The single BIM objects in open format have been inserted as IFC link and binded in the project environment.

- The BIM objects of the single IFC file have been copied and pasted in the project environment.

In the second step, we created a schedule from the category "Generic Model", selecting all the available information parameters. After completing all the information, in step three we experimented different methods to export the project file as an IFC file:

- For the project file in proprietary format, the IFC version "IFC $2 \times 3$ Coordination View 2.0" has been duplicated, switching the Property Sets from "Export IFC common property sets" to "Export Revit ${ }^{\circledR}$ property sets".

- For the project file in open format, the IFC version "IFC $2 \times 3$ Coordination View 2.0" has been duplicated, switching the Property Sets from "Export IFC common property sets" to "Export schedules as property sets".

- For components of the single IFC file, the IFC version "IFC $2 \times 3$ Coordination View 2.0" has been duplicated, switching the Property Sets from "Export IFC common property sets" to "Export schedules as property sets".

Again, through the IFC viewer BIMvision ${ }^{\circledR}$, each IFC file has been checked in order to test missing geometries and/or information. Then, the IFC files have also been uploaded into Revit ${ }^{\circledR}$, Allplan ${ }^{\circledR}$ and Archicad ${ }^{\circledR}$ to evaluate the effective possibility to exchange information between different BIM software using the open format.

We have also performed the first and the third steps with the software $\operatorname{Archicad}^{\circledR}$ and Allplan ${ }^{\circledR}$, in order to check the interoperability of the created IFC files. Details are discussed in the result section.

\section{RESULTS}

\subsection{Open format libraries}

Using the IFC viewer BIMvision ${ }^{\circledR}$ is possible to visualize the shaped geometry and the created information parameters. As illustrated in Figure 5: within the BIM software Revit ${ }^{\mathbb{R}}$, Archicad $^{\circledR}$ and Allplan ${ }^{\circledR}$ is possible not only to have access to the information but also to manipulate them.

\begin{tabular}{|c|c|c|c|c|c|c|c|c|}
\hline \multirow[t]{2}{*}{ OHIECI } & \multicolumn{2}{|c|}{ revit $\mathbf{R}$} & \multicolumn{2}{|c|}{ ALIPLAN $\Lambda$} & \multicolumn{2}{|c|}{ arcohicad $\boldsymbol{\Gamma}$} & \multicolumn{2}{|c|}{ HaM VISION Ge> } \\
\hline & mestry & 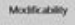 & Vreatery & 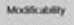 & meary & Mosticition & veacery & mosckediry \\
\hline Totem informativo & Complese & Allowed & Complete & Allowed & Compleze & Allowed & Complete & Not alowed \\
\hline Domino smal & Complese & Allowed & Complete & Allowed & Complete & Allowed & Complete & Not allowed \\
\hline Domino Large & Complese & Allowed & Complete & Allowed & Complese & Allowed & Complete & Not allowed \\
\hline TOi ontogonale & Complese & Nlomed & Complete & Nlowed & Compleste & Allowed & Complete & Not allowed \\
\hline TO1 inclinate & Complete & Allowed & Complete & Allowed & Complese & Allowed & Complete & Not allowed \\
\hline $\mathrm{TO} 2$ & Comploto & Allowod & Complete & Allowed & Complote & Allowod & Complote & Not allowed \\
\hline T03 singolo & Complete & Allowed & Complete & Allowed & Complete & Allowed & Complete & Not allowed \\
\hline T03 doppio & Complere & Allowed & Complete & Allowed & Complese & Allowed & Complete & Not allowed \\
\hline 104 singolo & Complese & Allowed & Complete & Allowed & Complete & Allowed & Complete & Not allowed \\
\hline T04 doppio & Complese & Allowed & Complete & Allowed & Complete & Allowed & Complete & Not allowed \\
\hline IOS doppio & Complese & Allowed & Complete & Allowed & Complese & Allowed & Complete & Not allowed \\
\hline TOS tiplo & Complese & Allowed & Complete & Allowed & Complese & Allowed & Complete & Not allowed \\
\hline
\end{tabular}

Figure 5: Results by opening the single IFC files with different BIM software. 
4.2 Parallelism between the proprietary format and the open format

In this section, we discuss the differences we have observed in completing the three selected tasks with each developed library. We present the performance of each task, describing the differences between the three libraries.

4.2.1 Positioning the BIM objects in the project environment

The measured differences highlight how Revit ${ }^{\circledR}$ reads the objects of the different libraries. Referring to the proprietary format library, Revit ${ }^{\mathbb{R}}$ recognises the loaded objects as Revit Families, and keeps the instance and type parameters under the defined groups. Referring to the open format library made of a group of IFC files, when uploading a single BIM object into the project environment, Revit ${ }^{\circledR}$ reads the geometry of the object as a model group visualizing both instance and type parameters under the group "IFC Parameters". When a second BIM object in IFC format is uploaded into the project environment, Revit ${ }^{\mathbb{B}}$ reports all the parameters related with this second object, even if these parameters are the same already uploaded by the first object. This situation results in a list of duplicated parameters. Moreover, only one of the two duplicated parameters has a value assigned, while the value linked with the other parameter is lost. Uploading a third IFC object, the same parameter appears three times and, for each object, only one of the repeated parameters has a value, and so on linking other IFC files. Figure 6: is representative of this situation in the case of two BIM objects uploaded in the same project environment. Importing the open format library made of a single IFC file, Revit ${ }^{\mathbb{R}}$ reads the copied components as single BIM objects. Selecting each object, Revit ${ }^{\circledR}$ shows instance and type parameters under the group "IFC Parameters", without repeating any parameter, regardless of how many objects we have pasted in the Revit ${ }^{\circledR}$ project file.

\subsubsection{Quantity and costs calculation}

A schedule has the main purpose of displaying costs and quantity, in order to develop a cost and a quantity estimation. When using the proprietary format library, Revit ${ }^{\circledR}$ generates schedules only with Revit ${ }^{\circledR}$ Built-in Parameters. To schedule personalized parameters into a project environment, it is necessary to re-create each parameter as Shared or Project parameter. With both the open format libraries, it is possible to generate schedules with all the personalized parameters already collected into the BIM objects. As illustrated in Fig. 7

\begin{tabular}{|c|c|}
\hline Family(Generic Model Schedule) & \\
\hline \multicolumn{2}{|l|}{ Cost(Generic Model Schedule) } \\
\hline \multicolumn{2}{|l|}{ STA_1.Classe di unità tecnologica(Generic Model ... } \\
\hline \multicolumn{2}{|l|}{ STA_2.Unità tecnologica(Generic Model Schedule) } \\
\hline \multicolumn{2}{|l|}{ STA_3.Classe di elemento tecnologico(Generic M... } \\
\hline \multicolumn{2}{|l|}{ IfCPropertysetList } \\
\hline If Name & orologio con pilastro:orologio con pilastro: 388022 \\
\hline \multicolumn{2}{|l|}{ IfeDescription } \\
\hline IfcExportAs & IfcBuildingElementProxyType.NOTDEFINED \\
\hline ObjectTypeOverride & orologio con pilastro \\
\hline If Presentationlayer & A-000-M_MASS \\
\hline IfcSpatialContainer & Level 0 \\
\hline IfcTag & 388022 \\
\hline Family(Generic Model Schedule) & orologio con pilastro: orologio con pilastro \\
\hline Cost(Generic Model Schedule) & 1500.00 \\
\hline STA_1.Classe di unità tecnologica(Generic Model ... & 4 Infrastrutture \\
\hline STA_2.Unità tecnologica(Generic Model Schedule) & 4.4 Arredo urbano \\
\hline STA_3.Classe di elemento tecnologico(Generic M... & 4.4.12 Orologio \\
\hline IfcPropertySetlist & "Generic Model Schedule" \\
\hline
\end{tabular}

Figure 6: Example of duplicated parameters when uploading each BIM objects as a single file into the project environment in Autodesk Revit ${ }^{\circledR}$. 

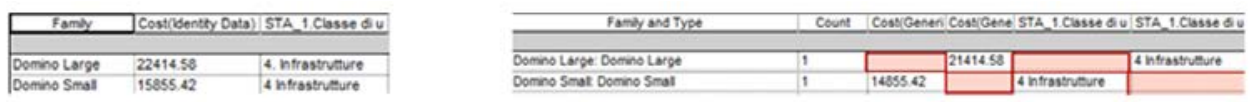

Figure 7: Comparison of the schedule generated using the single IFC file (on the left) and the schedule generated using the group of IFC files (on the right).

the main difference between the two open libraries regards how Revit ${ }^{\circledR}$ displays the generated schedule. In the open format library from a group of IFC files, due to the duplication of parameters described in Section 4.2.1, the schedule appears as a chessboard, with some parameters completed and other without a value. In the open format library from a single IFC file, the schedule results completed with all the parameters and the related values as defined during the creation of the library.

\subsubsection{Exporting the project as an IFC file}

In order to check the successful exporting of the project in IFC format, we verified the presence of geometric and alphanumeric information with the IFC viewer BIMvision ${ }^{\circledR}$ and the BIM software Revit ${ }^{\circledR}$, Allplan ${ }^{\circledR}$ and Archicad ${ }^{\circledR}$.

When using the proprietary format library, all the information exported are preserved and easily visualized into the IFC viewer and the BIM software. When using the open format library from a group of IFC files, geometric information is all preserved, while alphanumeric information is randomly missed. This non-sense loss of information has been detected with the IFC viewer and the BIM software, while any kind of missing information has been detected when using the open format library from a single IFC file.

\subsection{Interoperability}

The results show that it is possible to set IFC files in the project environment using Revit ${ }^{\mathbb{R}}$, Allplan ${ }^{\circledR}$ and Archicad ${ }^{\circledR}$. In addition to that, users may export another IFC file, after having modified alphanumeric information.

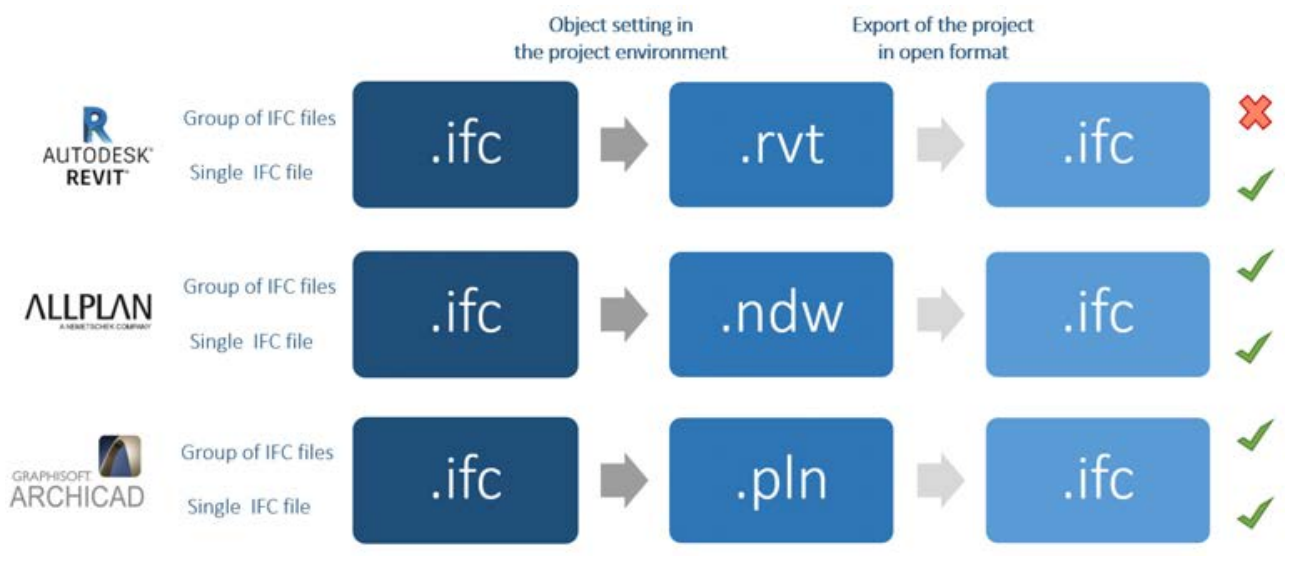

Figure 8: The image shows the results of the tests about information transmission, following the workflows connected to the three BIM software. 
As shown in Fig. 8, only one case shows an unsuccessful workflow. This unsuccessful result regards the export of the project as an IFC files in Autodesk Revit ${ }^{\mathbb{R}}$. The workflow suffers from randomly missing parameters in the BIM objects. We also noticed that it is possible to overcome this issue by completing the duplicated parameter without a value. This solution is clearly not sustainable with an increasing number of linked IFC files, unless establishing an automated system for completing parameters values. In all the other cases, the workflows do not show any error and BIM objects meet the needs of the public organization.

\section{DISCUSSION AND CONCLUSIONS}

Considering the point of view of the public organization and a simulation of its interaction with project partners, we highlight the benefits and the drawbacks of both proprietary and open format.

\subsection{The proprietary format}

The library in proprietary format $\left(\right.$ Revit $\left.^{\circledR}\right)$ presents the following strengthens:

- Seamless modifiability within the native software.

- Possibility to create several types within a single object family.

- Faster exchange of information using the same BIM software.

At the same time the proprietary format presents also some weakness, regarding:

- Limit in exchanging of information using different BIM software.

- Re-creation of the personalized parameters as Shared or Project parameters. This operation may be extremely time consuming, considering the number of parameters and the number of objects in a project environment.

5.2 The open format

The open format library as a group of IFC files:

- $\quad$ Is readable by BIMvision ${ }^{\circledR}$, Allplan $^{\circledR}$ and Archicad $^{\circledR}$.

- $\quad$ Is exportable by Allplan ${ }^{\circledR}$ and Archicad ${ }^{\circledR}$.

- Shows problems (duplication of information with loss of values) in the Revit ${ }^{\circledR}$ software.

- $\quad$ Results unsuccessful by exporting an IFC file from Revit ${ }^{\circledR}$.

The open format library as a single IFC file:

- Is completely software independent.

- Can support the public organization in different project phases.

- Can be a reference along the entire life cycle of the components.

- Seems to perform each established task without any issue.

In conclusion, it can be stated that both proprietary and open formats are efficient solution when developing a BIM library for a public organization. However, their usefulness depends on the way the public organization choose to organize its BIM adoption. The proprietary format is the appropriate solution if the public organization is allowed to organize its BIM adoption based on a specific software solution. However, Italian public organizations must assure the interoperability of the process using open, non-proprietary formats when procuring 
public works 0 . Therefore, it is essential the availability of an open format BIM library. Results of this research shows that an open format BIM library as a group of single files enhances information exchange of BIM objects only outside the project environment. Since the aim of this research is to develop a BIM library to improve the efficiency in information exchange between public organizations and their project partners at project level, this solution is not appropriate. The BIM library as a single IFC file pushes efficiently the exchange of information within the project environment, independently from the BIM environment adopted. Tasks are performed without any loss of information and therefore the interoperability is assured.

Further research activities on this topic will concern the use of the BIM objects library in a real project environment, evaluating the simulations run during this research project. Moreover, further research activities will focus on the management of a BIM objects library. The BIM library developed within this research project includes 30 components, but the number of components is supposed to increase intensively in the future. Therefore, a BIM library as a single IFC file could turn into a non-effective way of use. A further investigation may analyse how BIM object library should be organized in order to streamline the search for a specific component of the library.

\section{ACKNOWLEDGEMENT}

The authors gratefully acknowledge STA - Strutture Trasporto Alto Adige who provided important information and drawings for the development of this research.

\section{REFERENCES}

[1] Wong, A.K.D., Wong, F.K.W. \& Nadeem, A., Attributes of building information modelling implementations in various countries. Architectural Engineering and Design Management, 6, pp. 288-302, 2010.

[2] Sacks, R., Gurevich, U. \& Shrestha, P., A review of building information modeling protocols, guides and standards for large construction clients. Journal of Information Technology in Construction, 21, pp. 479-503, 2016.

Decreto legislativo n. 50 del 18 aprile 2016, Gazzetta Ufficiale della repubblica italiana. www.gazzettaufficiale.it/atto/serie_generale/caricaDettaglioAtto/originario? atto.dataPubblicazioneGazzetta=2016-04-19\&atto.codiceRedazionale=16G00062 .

Accessed on: 28 Jun. 2019.

[3] BIM Report Alto Adige 2018, Fraunhofer Italia Research. www.fraunhofer.it/content/ dam/italia/it/documents/per_il_sito_BIM\%20report\%20Alto\%20Adige_GT_Version e\%20per\%20PDF.pdf. Accessed on: 28 Jun. 2019.

[4] Reddy, K.P., BIM for Building Owners and Developers: Making a Business Case for Using BIM on Projects, John Wiley \& Sons, 2011.

[5] Cavka, H.B., Staub-French, S. \& Poirier, E.A., Developing owner information requirements for BIM-enabled project delivery and asset management. Automation in Construction, 83, pp. 169-183, 2017.

[6] Ente nazionale italiano di unificazione, UNI EN ISO 11337-1: 2017 Edilizia e opere di ingegneria civile - Gestione digitale dei processi informativi delle costruzioni Parte 1: Modelli, elaborati e oggetti informativi per prodotti e processi.

[7] Afsari, K. \& Eastman, C., Categorisation of building product models in BIM content library. Blucher Design Proceedings, 1(8), pp. 370-374, 2014.

[8] Shin, J., Choi, J., Inhan, K. \& Yoon, D., A study on development of integrated management system for BIM property information. Transactions of the Society of CAD/CAM Engineers, 21(2), pp. 130-142, 2016. 
[9] Hjelseth, E., Exchange of relevant information in BIM objects defined by the role- and life-cycle information model. Architectural Engineering and Design Management, suppl. Special Issue: Integrated Design and Delivery Solutions, 6, pp. 279-287, 2010.

[10] Matarneha, S.T., Danso-Amoakob, M., Al-Bizri, S., Gaterell, M. \& Matarneh, R., Developing an interoperability framework for building information models and facilities management systems. Creative Construction Conference, pp. 1018-1027, 2018.

[11] National Institute of Standards and Technology, Cost analysis of inadequate interoperability in the U.S. capital facilities industry. www.lagospm.com/03-benefits/ articles/NIST.pdf. Accessed on: 28 Jun. 2019.

[12] Lee, C.J. \& Lim, S.H., A study on development of BIM library for unit modular housing-focused on small-sized urban-life-housing. Journal of the Korean Housing Association, 23(6), pp. 11-20, 2012.

[13] Eastman, C.M., Teichol, Z.P., Sacks, R. \& Liston, K., BIM Handbook: A Guide to Building Information Modeling for Owners, Managers, Designers, Engineers and Contractor, John Wiley \& Sons, 2011.

[14] Ente nazionale italiano di unificazione, UNI EN ISO 11337-4: 2017 Edilizia e opere di ingegneria civile - Gestione digitale dei processi informativi delle costruzioni - Parte 4: Evoluzione e sviluppo informativo di modelli, elaborati e oggetti, 2017.

[15] Deutsche Bahn, BIM Strategie. www.deutschebahn.com/de/bahnwelt/bauen_bahn/ bim/BIM-1186016._Accessed on: 28 Jun. 2019.

[16] NBS National BIM Library, NBS platform. www.nationalbimlibrary.com/en/. Accessed on: 28 Jun. 2019.

[17] Nawari, O.N. \& Kuenstle, M., Building Information Modeling: A Framework for structural design, CRC Press, 2015.

[18] Pasini, D., Caffi, V., Daniotti, B. \& Pavan, A., The INNOVance BIM library approach. Innovative Infrastructure Solutions, 2(1), 2017. 